\title{
Capability Maturity Model Integrated for Ship Design and Construction
}

\author{
Serena Caracchi ${ }^{1}$, Pavan Kumar Sriram ${ }^{2}$, Marco Semini ${ }^{2}$, and Jan Ola Strandhagen ${ }^{2}$ \\ ${ }^{1}$ Dept. of Engineering, University of Bergamo, Bergamo, Italy \\ serenac@stud.ntnu.no \\ ${ }^{2}$ Dept. of Production and Quality Engineering, \\ Norwegian University of Science and Technology, Trondheim, Norway \\ \{pavan.sriram, marco.semini\}@ntnu.no, \\ Janola.Strandhagenesintef.no
}

\begin{abstract}
Project constraints are continuously growing in terms of time, cost, customer satisfaction, return on investment, quality. And also they are growing in terms of complexity, number of stakeholders, number of parameters to manage and number of interactions between these parameters. In this paper, we carry out literature study on capability maturity model integrated (CMMI) for Ship Design and Construction. The purpose is to understand, demonstrate and develop a structure for CMMI in Ship Design and Construction. Capability maturity models offer companies a simple but effective tool to organize, control and monitoring their processes. Emerged out of software engineering, the application fields have widened and maturity model research is becoming more important. So far, few limited studies exits on applicability of capability maturity models for Ship Design and Construction. The developed structure can be used as a structured matrix to assess the maturity levels of the company through measurable stages. In addition, the structured matrix can be used to assess and improve individual companies involved in the ship design and construction process, for example a yard and assess various value chain configurations, i.e., alternative configurations of actors to be performing a planned ship design and construction project.
\end{abstract}

Keywords: Ship Design and Construction, CMMI, maturity models, value chain configurations.

\section{$1 \quad$ Introduction}

Ship design and construction involves integrated activities, that includes tendering, contracting, concept and functional design, engineering, procurement, production, commissioning, delivery, and guarantee service (Andritsos and Perez-Prat 2000). In recent years, the ship design and construction community has become increasingly aware of the significance of the operational and managerial side of such activities, if they are to be effectively performed, coordinated and integrated (Semini et al., 2014). However, there is a lack of models and tools supporting the assessment, improvement and integration of these activities. Within project management in general, various 
models for internal assessment and improvement of process quality/capability have been proposed. Among them, the capability maturity model (CMM) and its successor, capability maturity model integrated, (Chrissis et al., 2003) seem to be particularly suitable for more specific application in various sectors. Attempts have been made to adapt them to the industry characteristics within fashion (Battista and Schiraldi 2013), the automotive industry (Gonzalez et al., 2007), construction (Meng et al., 2011), and mechatronics and transportation (Pels and Simons 2008). To the authors' knowledge, no such studies have been performed for ship design and construction industry. This study seeks to fill the knowledge gap by developing a structure for a CMMI for ship design and construction. It aims to identify the activities the CMMI should evaluate (criteria), as well as the maturity levels in each of these activities. The main result of this paper is the CMMI matrix which could be used as a tool to assess and improve the capabilities of individual companies involved in the ship design and construction process, for example, a yard. It may also be in project-making in order to assess alternative configurations of actors to be performing a planned ship design and construction project. The concepts and results developed in the present research are mainly based on a literature review. International journals and conference proceedings, scientific textbooks, as well as white papers and relevant internet sources have been used in order to understand ship design and construction as well as to review existing research on maturity models.

\section{Ship Design and Construction}

Ships differ regarding the level of required customization, demand volumes and other characteristics (Semini et al., 2014). Ship design and construction is a complex process in which a lot of resources and areas of the company are involved, and requests a high level of coordination between parties. The project starts with the concept design, where customer requirements are translated into first set of documents with the principal characteristics of ships (area, volume, weight, speed). Then there's a deeper level, called basic and functional design, in which is created a specification book that collects technical details of the entire system and theirs economic feasibility. The contract design is built on a platform in which customer, yards, designers and engineers and constructions parties agree on specifications and costs about the entire project; the platform is continuously update.

Through engineering activities concept design is translated into drawings, sketches and concrete instructions to build the ship. In this step the ship project is integrated with the different systems and subsystems (electrical, control,...) and often the engineering is carried out concurrently with procurement and production. Planning and coordination is an essential activity to conclude the work on time. Essentially the building strategy is decided (how to build and with what), costs and time are estimated and the main schedule is anticipated. Finally the construction of the ship is carried out in the production and assembly stage, starting with the hull and finishing with the assembly of the various subsystems. After all the work in the dry dock is finished, the ship is launched on water. The procurement concerns the selection, the negotiation and the collaboration with suppliers. It's also a very important activity because it's necessary to complete it in little time, from the signed contract and the 
start of work. Then there's the commissioning, in which a long period test is carried and the ship is delivered to the buyer. The ship design and construction company agrees on maintenance and carries routine maintenance at an agreed time basis.

Above we introduced the main activities performed in ship design and construction. It did not distinguish between the ship designer and the ship builder (yard). In some cases, there are indeed fully integrated firms that carry out a large part of the project in-house and sometimes even own the finished product. Usually, however, the different activities are not performed by a single company, but a network of geographically dispersed parties with different roles and interactions. Even a single activity, such as engineering, can be split among several parties. The degree to which each party is involved in the various activities differs from project to project, and so does the level of integration and coordination between them. This is a characteristic of ship design and construction. Due to these differences, we find it useful to name the involved parties in terms of their predominant function. We concentrate on those with the most significant roles in actually carrying out the ship design and construction activities:

- The ship designer

- The shipyard

- Main equipment suppliers

\section{CMMI: An Overview}

\subsection{Review of Existing Models}

Maturity models generally arose at the beginning of the nineties when companies started to feel the need to assess the current state of their organizations in a structured way (Kohoutek 1996). Today, there are many different models, each oriented towards a specific domain (Table 1):

Table 1. Existing maturity models

\begin{tabular}{|c|c|c|}
\hline Model & Domain & Developer and key reference \\
\hline $\begin{array}{c}\text { Capability } \\
\text { Maturity } \\
\text { Model Integration (CMMI) }\end{array}$ & Management & $\begin{array}{l}\text { Carnegie Mellon } \\
\text { University, Chrissis, Konrad et al. (2003) }\end{array}$ \\
\hline $\begin{array}{l}\text { Enterprise } \\
\text { Architecture } \\
\text { Maturity Model }\end{array}$ & $\begin{array}{c}\text { IT } \\
\text { Management }\end{array}$ & $\begin{array}{c}\text { National } \\
\text { Association of State CIO's (www.nascio.org/hotIs } \\
\text { sues/EA/EAMM.pdf) }\end{array}$ \\
\hline $\begin{array}{c}\text { European Foundation for Quality } \\
\text { Management (EFQM) Excellence Model }\end{array}$ & $\begin{array}{c}\text { Business } \\
\text { Management }\end{array}$ & EFQM, Wongrassamee, Simmons et al. (2003) \\
\hline Process Maturity Model & $\begin{array}{c}\text { Process } \\
\text { Management }\end{array}$ & $\begin{array}{c}\text { Rummler- Brache Group,(www.rummler- } \\
\text { brache.com) }\end{array}$ \\
\hline Project Management Maturity Model (PM3) & $\begin{array}{c}\text { Project } \\
\text { Management }\end{array}$ & $\begin{array}{c}\text { Office of } \\
\text { Government Commerce, UK (www.ogc.gov.uk/sdtoo } \\
\text { lkit/reference/tools/PMMM_ } \\
\text { release_v5.pdf) }\end{array}$ \\
\hline $\begin{array}{c}\text { Portfolio, } \\
\text { Programme and } \\
\text { Project Management Maturity Model (P3M3) }\end{array}$ & $\begin{array}{c}\text { Project } \\
\text { Management }\end{array}$ & $\begin{array}{c}\text { AXELOS } \\
\text { Limited (www.p3m3-officialsite.com/AboutP3M3/ } \\
\text { AboutP3M3.aspx) }\end{array}$ \\
\hline $\begin{array}{c}\text { Organizational } \\
\text { Project Management Maturity Model (OPM3) }\end{array}$ & $\begin{array}{c}\text { Project } \\
\text { Management }\end{array}$ & PMI , Farrokh and Mansur (2013) \\
\hline
\end{tabular}


Among the reviewed models CMMI appears to be particularly suitable for application to ship design and construction. First of all, CMMI reduces task uncertainty and helps manage complex interaction among actors, tasks and processes; this leads to a reduction in defects and rework. It supports process integration and the reuse of past knowledge, reducing time and costs. And another significant benefit is that it helps to integrate supply chains, contributing towards effective relationship management (Veldman and Klingenberg 2009). Quality schemes, such as ISO 9001:2000 and DNVs Manufacturer product quality assessment (MPQA) are outwards oriented, aiming to provide certifications towards customers and stakeholders (Bozarth and Edwards 1997). Maturity models, on the other hand, support internal assessment and improvement. They complement each other. ISO 9001:2000 has been associated with the third level in the CMMI structure (Yoo et al., 2006). Yoon et al. also proposed a method to implement both frameworks by initially implementing CMMI and adding further requirements for ISO 9001:2000. Further we define CMMI and discuss the maturity levels of CMMI in the following section.

\subsection{Definitions of CMMI}

Before defining a CMMI model is important to understand CMM model from which, CMMI is derived. The Capability Maturity Model is a framework representing a path of improvements recommended in order to reach a different stage of process capability (Paulk 1993). CMM integration (CMMI) is an extension of CMM model, composed by a collection of the best practices in the areas of product and service development, service establishment, management, delivery and product and service acquisition. There are two representation of CMMI: continuous and staged. The main difference between them is while the staged model rates the whole organization with one figure, a continuous model rates separately the performance of each of the processes that are assessed (Jokela et al. (2006), CMMI Product Team (2002)).

\subsection{The Levels and Benefits of CMMI}

In continuous representation CMMI has got six levels of maturity represented in figure 1 (CMMI Product Team (2002), Chrissis et al. (2003)):Incomplete (Level 0): In this level processes are not performed or partially not performed (every/some goals are not satisfied). Performed (Level 1): Process satisfies the specific goals of the process area but the procedures are not homogeneous. Managed (Level 2): Process is performed with a basic infrastructure in place to support itself. It is planned and executed in accordance with policy. People that work on it are skilled. Processes are also monitored, controlled and reviewed. Defined (Level 3): At this level processes are managed but also they follow precise guidelines about purposes, inputs, activities, roles, measures, criteria. Quantitatively Managed (Level 4): Defined processes are controlled using statistical and other quantitative techniques. With these is possible to handle quality and performances. Optimizing (Level 5): With a quantitatively managed process is possible to understand the different causes of variation in the process and improve it. For our matrix we ignore level 0. 

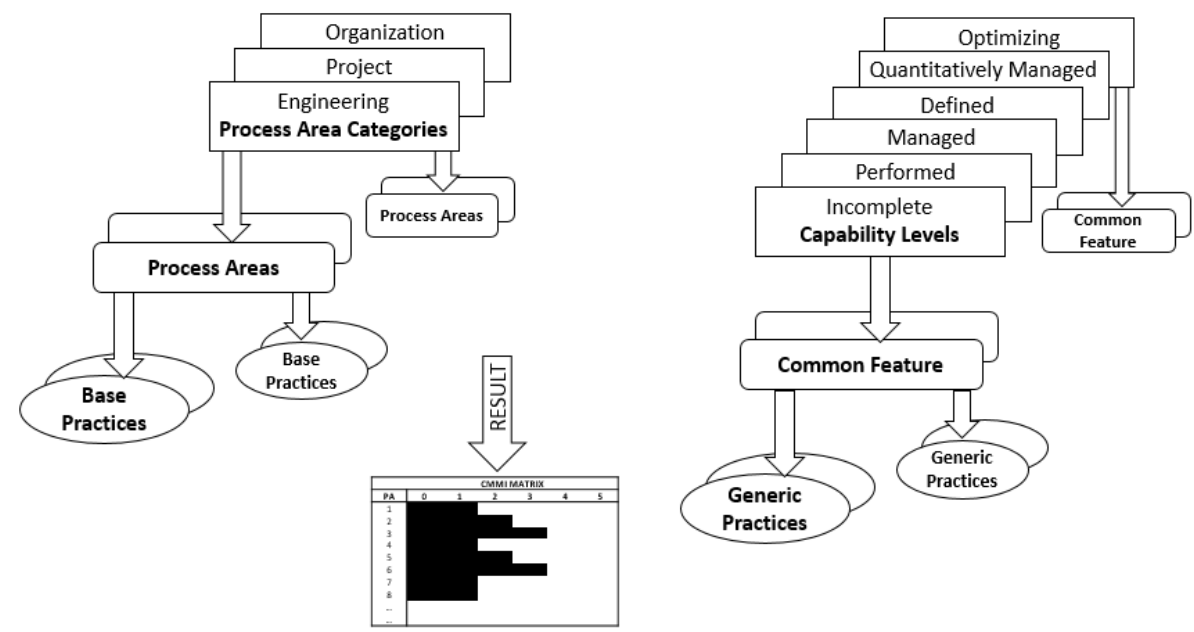

Fig. 1. CMMI model scheme

Benefits can vary during the different stages and for can be different for every company. But there are some general advantages that it is simple to lists. According to Goldenson and Gibson (2003) and Veldman and Klingenberg (2009), a CMMI maturity model can: increase customer satisfaction; reduce the costs of work products and the processes employed to produce; increase focus of quality with the reduction of defects over time; increase communication and coordination between actors; fit better the schedule of the project, improve the schedule predictability and reduce time required to do the work; improve productivity; reduce variability in lead times. Through the development of the structured matrix we aim to achieve similar benefits for ship design and construction.

\section{Towards CMMI for Ship Design and Construction}

The new model contains seven main criteria's. They are contract design, design and engineering, planning and coordination, production and assembly, procurement, logistics, and maintenance. However the main criteria's are not assess directly. Instead, each main criterion is broken down in three subcriteria. For example, the main criterion contract design is broken down into bidding, value chain configuration, negotiation and agreement. Both the main criteria's and subcriteria are developed on the basis of literature review (Meng et al. (2011), Veldman and Klingenberg (2009), Wendler (2012), James et al. (2012), Semini et al. (2014), Lamb (2004), Chrissis et al. (2003), Jokela et al. (2006), APM (2007), Netland et al. (2007), van Dokkum (2011)). The review of the literature on existing models also contributes to the identification of assessment criteria. In addition to the literature review, an expert group discussion confirms these indicators and gives a compliment.

As show in table 2, assessment criteria are described in a structured matrix. In the following matrix, the assessment descriptions of all criteria and subcriteria a different maturity levels are explained. This helps for in depth assessment. 
Table 2. CMMI model for shipbuilding

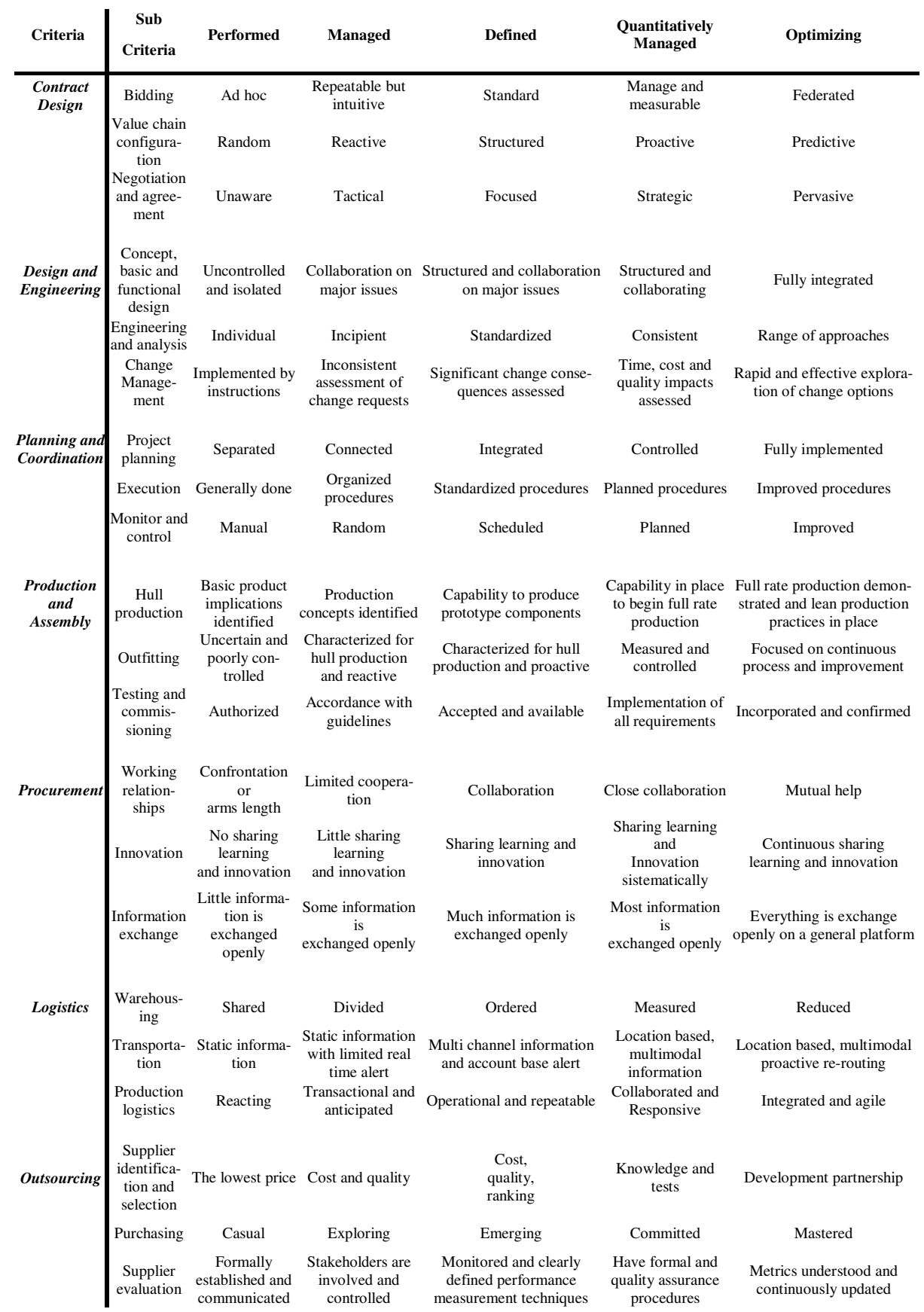




\section{Conclusions}

This paper has proposed a structure for a CMMI for ship design and construction. Based on a literature study, relevant criteria and subcriteria have been identified and maturity levels proposed for each subcriterion. The most direct application is for internal assessment and improvement purposes at yards and other actors involved in ship design and construction. In addition, the CMMI can be used when configuring the network of actors to be performing a ship design and construction project. For example, it may be applied to a number of yards that are candidates for the construction of a specific ship. This can support both the selection of yards as well as deciding which engineering, procurement, and production tasks to assign to the yard. The ultimate goal of using the CMMI is to contribute to effective completion of ship design and construction projects. It should help to meet ever-increasing requirements to flexibility and responsiveness at highest quality and lowest cost.

The current study is literature-based, and a natural next step is to test, refine, and operationalize the CMMI by means of a number of case studies. Moreover, opportunities to apply the model in other engineer-to-order segments should be investigated, for example the manufacturing of maritime equipment such as thrusters, winches, and cranes.

Acknowledgement. This research was made possible by the SUSPRO project (Decision support for sustainable production of offshore ships in global fluctuating markets) as well as SFI Norman. The authors would like to thank the participants of the project for providing the inputs and fruitful discussions.

\section{References}

1. Capability Reviews (MPQA), http://www.dnv.com/industry/maritime/servicessolutions / cmc/approvalofmanufacturers/capabilityreviews

2. Andritsos, F., Perez-Prat, J.: The automation and integration of production processes in shipbuilding. State-of-the-Art report, Joint Research Centre. European Commission, Europe (2000)

3. APM, Models to Improve the Management of Projects (2007)

4. Battista, C., Schiraldi, M.M.: The Logistic Maturity Model: Application to a Fashion Company. International Journal of Engineering Business Management (2013)

5. Bozarth, C., Edwards, S.: The impact of market requirements focus and manu-facturing characteristics focus on plant performance. Journal of Operations Management 15(3), 161-180 (1997)

6. Chrissis, M.B., et al.: CMMI Guidlines for Process Integration and Product Im-provement. Addison-Wesley Longman Publishing Co., Inc. (2003)

7. CMMI Product Team, Capability maturity model@ integration (CMMI SM), ver-sion 1.1. Software Engineering Institute, Carnegie Mellon University, Pittsburg, PA, Tech. Rep. SEI-2002-TR-012 (2002) 
8. Farrokh, J., Mansur, A.K.: Project Management Maturity Models and Organizational Project Management Maturity Model (OPM3®): A Critical Morphological Evaluation. Project Management 2(7), 23-33 (2013)

9. Goldenson, D., Gibson, D.L.: Demonstrating the impact and benefits of CMMI: an update and preliminary results (2003)

10. Gonzalez, N., et al.: Measuring project maturity: example in a french automotive organization. International Conference on Engineering Design, ICED O (2007)

11. James, P., et al.: Key characteristics of SME procurement: An empirical study (2012)

12. Jokela, T., et al.: A survey of usability capability maturity models: implications for practice and research. Behaviour \& Information Technology 25(03), 263-282 (2006)

13. Kohoutek, H.J.: Reflections on the capability and maturity models of engineering processes. Quality and Reliability Engineering International 12(3), 147-155 (1996)

14. Lamb, T.: Ship design and construction, Society of Naval Architects and Marine Engineers (2004)

15. Meng, X., et al.: Maturity Model for Supply Chain Relationships in Construction. Journal of Management in Engineering 27(2), 97-105 (2011)

16. Netland, T.H., et al.: How mature is your supply chain?-A supply chain maturity assessment test. In: Proceedings of the 14th International EurOMA Conference Managing Operations in an Expanding Europe (2007)

17. Paulk, M.: Capability maturity model for software, Wiley Online Library (1993)

18. Pels, H.J., Simons, K.: PLM maturity assessment. ICE, The 14th International Conference on Concurrent Enterprising: Concurrent Innovation: A New Wave of Innovation in Collabarative Networks, Lisbon, Portugal (June 2008)

19. Semini, M., et al.: Strategies for customized shipbuilding with different customer order decoupling points. Proceedings of the Institution of Mechanical Engineers, Part M: Journal of Engineering for the Maritime Environment (2014) 1475090213493770

20. van Dokkum, K.: Ship Knowledge: Ship Design, Construction and Operation, Dokmar (2011)

21. Veldman, J., Klingenberg, W.: Applicability of the capability maturity model for engineerto-order firms. International Journal of Technology Management 48(2), 219-239 (2009)

22. Wendler, R.: The maturity of maturity model research: A systematic mapping study. Information and software technology 54(12), 1317-1339 (2012)

23. Wongrassamee, S., et al.: Performance measurement tools: the Balanced Scorecard and the EFQM Excellence Model. Measuring Business Excellence 7(1), 14-29 (2003)

24. Yoo, C., et al.: A unified model for the implementation of both ISO 9001: 2000 and CMMI by ISO-certified organizations. Journal of System and Software 79(7), 954-961 (2006) 